\title{
Light chain multiple myeloma, clinic features, responses to therapy and survival in a long-term study
}

Jia-jia Zhang ${ }^{1+}$, Wan-jun Sun ${ }^{2 \dagger}$, Zhong-xia Huang ${ }^{1}$, Shi-lun Chen ${ }^{1}$, Yu-ping Zhong ${ }^{1}$, Ying Hu${ }^{1}, \mathrm{Na} A n^{1}$, Men Shen ${ }^{1}$ and Xin $\mathrm{Li}^{i^{*}}$

\begin{abstract}
Background: We intended to investigate the long-term clinical characteristics, responses to therapy and survival in patients with lightchain multiple myeloma (MM).

Methods: Ninety-six patients were enrolled into the study. There were $42 \mathrm{~K}$-chain MM patients and $54 \lambda$-chain MM patients. All the patients werestage III in the Durie-Salmonstaging system. Among them, 66 patients received Velcade (bortezomib) treatment and the other 30 did not.

Results: The main symptoms of these patients included bone pain (77.1\%), weakness and fatigue (12.5\%), foamy urine (8.3\%) and extramedullaryplasmocytomas (33.3\%). The overall response rate (ORR) was $95.5 \%$ in patients treated with Velcade and 60\%in the patients without. The median survival times were 23 months in patients treated with Velcade and 12 months in patients without. The median time of progression-free survival (PFS) was nine months in patients treated with Velcade and five months in patients without. The one-year PFS and two-year PFS were 37\% and 25\%, 27\% and 9\% for patients treated with Velcade, or without, respectively. The three-year overall survival (OS) and five-year OS were 33\% and 24\%, 28\% and 9\% for patients treated with Velcade, or without, respectively. There was no significance in OS between the two groups $(P=0.335)$. But there was significant difference in PFS between the two groups $(P=0.036)$.
\end{abstract}

Conclusions: Our long-term study demonstrated that patients with lightchain myeloma appeared to have more aggressive disease courses and poor outcomes, which could be improved by treatment with Velcade.

Keywords: Multiple myeloma, Light chain myeloma, Velcade, Survival

\section{Background}

Multiple myeloma (MM), a malignant lymphoproliferative B-cell disease characterized by the accumulation of monoclonal plasma cells in the bone marrow, is the second most frequent hematological malignancy [1,2]. The most common type of M-protein found in MM is immunoglobulin (Ig)G followed by IgA and light chain only. An exclusive production of light chains can be found in 15\% of myeloma cases. Renal failure, bone disease and amyloidosis appear to be more frequent in these patients.

\footnotetext{
*Correspondence: xinli562@yahoo.com

${ }^{\dagger}$ Equal contributors

'Department of Hematology and Oncology, Beijing Chaoyang Hospital, Capital Medical University, Jingyuan Road, Beijing 100043, China

Full list of author information is available at the end of the article
}

Lightchain multiple myeloma also appears to have a poorer prognosis than IgG and IgA subtypes when treated with chemotherapy. However, the outcomes in the light chain subtype have not been addressed specifically.

Velcade (bortezomib) is a first-in-class proteasome inhibitor, initially approved by the US Food and Drug Administration (FDA) and the European Agency for the Evaluation of Medicinal Products (EMEA) for patients with relapsed and refractory $\mathrm{MM}$ who have received at least two prior lines of therapy and progressed onto their last therapy $[3,4]$. In the present study, we conducted a long-term study (eightyears) to report the clinical characteristics, responses to therapy and survival in patients with light chain MM while they were either treated with Velcade or not.

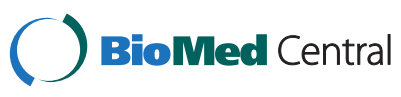


Table 1 The characteristics of 96 light chain multiple myeloma patients

\begin{tabular}{|c|c|c|c|c|}
\hline Characteristics & With Velcade group $(n=66)$ & Without Velcade group $(n=30)$ & Total & $P$ value \\
\hline Age(years) & $59(28-86)$ & $58(43-77)$ & $58(28-86)$ & $>0.05$ \\
\hline Sex(male/female) & $34 / 29$ & $17 / 16$ & $51 / 45$ & $>0.05$ \\
\hline Albumin(g/L) & $33.7(24.1-43.2)$ & $32.1(17-42.4)$ & $33.2(17-43.2)$ & $>0.05$ \\
\hline Leucocyte(X109/L) & $5.4(1.0-11.7)$ & $4.4(1.5-8.3)$ & $5.1(1.0-11.7)$ & $>0.05$ \\
\hline Hemoglobin(g/L) & 95.3(43-139) & $99.3(51-140)$ & $96.5(43-140)$ & $>0.05$ \\
\hline Platelet(X109/L) & 189(33-389) & 180(34-513) & $186(33-513)$ & $>0.05$ \\
\hline C-reactive protein(mg/L) & $12.76(0.62-60)$ & 16.71(5.0-80) & $13.89(0.62-80)$ & $>0.05$ \\
\hline Sedimentation(mm/h) & $52(1.0-170)$ & $53(2-140)$ & $52(1-170)$ & $>0.05$ \\
\hline B2-microglobulin(mg/L) & $7.51(1.06-38.15)$ & $9.01(0.89-41.5)$ & 7.96(0.89-41.5) & $>0.05$ \\
\hline Bone marrow plasmacytosis(\%) & $34.7(0.5-84)$ & $40.2(3.5-95)$ & $36.4(0.5-95)$ & $>0.05$ \\
\hline Lactate dehydrogenase(U/L) & $179.5(91-849)$ & 179.4(112-256) & 179.5(91-849) & $>0.05$ \\
\hline Uric acid(umol/L) & $346(130-590)$ & $344(128-517)$ & $345(128-590)$ & $>0.05$ \\
\hline Serum creatinine(umol/L) & $177.3(21.7-724.2)$ & $108.5(31.27-507)$ & $157.4(21.7-724.2)$ & $>0.05$ \\
\hline Light chain(g/24 hour) & 23.9(1.0-128.8) & $23.4(1.2-89.0)$ & $23.8(1.2-128.8)$ & $>0.05$ \\
\hline
\end{tabular}

\section{Methods}

\section{Patients}

Ninety-six cases of light chains multiple myeloma at Beijing Chao Yang Hospital and the Second Artillery General Hospital deriving from a series of 459 symptomatic patients with MM were included into this study from June 2005 to December 2012. There were 51 men and 45 women. The median age was 58 years (range, 28 to 86 years), and all these patients were accorded with multiple myeloma diagnostic criteria 1 . These patients were staged according to International Staging System (ISS) and Durie-Salmon (DSS) staging system. Extramedullaryplasmocytomas were examined by magnetic resonance imaging (MRI) or computed tomography (CT), or were identified by the treatment effect pathology criterion with reference to the International Myeloma Working Group (IMWG).

\section{Clinical examination}

For the examination of treatment responses, progressionfree survival (PFS) and overall survival (OS), the patients were divided into two groups, the Velcade group (66 cases) and the without Velcade group (30 cases). For patients in the Velcade group, Velcade $\left(1.0 \mathrm{mg} / \mathrm{m}^{2}\right)$ and dexamethasone $(20 \mathrm{mg}$ ) were given at days $1,4,8,11$. For patients without Velcade, they were given melphalan

Table 2 Clinical type of 96 light chain multiple myeloma patients

\begin{tabular}{llll}
\hline Group type & $\mathbf{~}$ & $\boldsymbol{\lambda}$ & $\mathbf{( к / \lambda )}$ \\
\hline Velcade group $(n=66)$ & 28 & 38 & $28 / 38$ \\
Without Velcade group $(n=30)$ & 14 & 16 & $14 / 16$ \\
Total & 42 & 54 & $42 / 54$ \\
\hline
\end{tabular}

$8 \mathrm{mg} / \mathrm{m}^{2}$ and prednisone $60 \mathrm{mg} / \mathrm{m}^{2}(\mathrm{MP})$ orally between days 1 and 4 . Vinblastine $1.2 \mathrm{mg} / \mathrm{m}^{2}$ (M2) and simustine $20 \mathrm{mg} / \mathrm{m}^{2}$ (Me-CCUN) were given only at day 1 . Also, vinblastine $0.4 \mathrm{mg}$ days 1 to 4 , epirubicin $10 \mathrm{mg}$ days 1 to4, dexamethasone $20 \mathrm{mg}$ (VAD) at days 1 to 4,9 to12) or ifosfamide $0.5 \mathrm{~g}$ days 1 to 4 , dexamethasone $20 \mathrm{mg}$ days 1 to4, thalidomide $100 \mathrm{mg}$ (CTD) each night were administered. All the patients had completed at least four cycles of Velcade or chemotherapy and had been evaluated for response to therapy after four cycles of therapy.

\section{Statistical analysis}

The Kaplan-Meier method was used to estimate the probability of progression-free survival (PFS) and overall survival (OS). The log-rank test was used to compare PFS and OS durations among different groups. PFS was defined as the time from complete remission (CR) to relapse and progression, death from any cause, or censoring of the data on the patients. OS is defined as the time from registration to death or censoring of the data on the patients. For all other statistical analysis between Velcade and non-Velcade groups, a Student's ttest (SPSS version 11.0) was used. Statistical significance was determined if $P<0.05$.

Table 3 Durie-Salmon and International Staging System (ISS) staging of 96 light chain multiple myeloma patients

\begin{tabular}{llllllll}
\hline Group subtype & \multicolumn{2}{l}{ Durie-Salmon staging } & & \multicolumn{2}{l}{ ISS staging } \\
\cline { 2 - 3 } & IIIA & IIIB & & & II & III \\
\hline Velcade group $(n=66)$ & 36 & 30 & & 9 & 17 & 40 \\
Without Velcade group $(n=30)$ & 24 & 6 & & 3 & 9 & 18 \\
Total & 60 & 36 & & 12 & 26 & 58 \\
\hline
\end{tabular}


Table 4 The symptoms of 96 multiple myeloma patients producing light chain immunoglobulin

\begin{tabular}{llll}
\hline Symptoms & $\begin{array}{l}\text { Velcade group } \\
(\mathbf{n}=\mathbf{6 6})\end{array}$ & $\begin{array}{l}\text { Without } \\
\text { Velcade group } \\
(\mathbf{n = 3 0 )}\end{array}$ & Total \\
\hline Weakness and fatigue & 10 & 2 & 12 \\
Bone pain & 51 & 23 & 74 \\
Foam urine & 4 & 4 & 8 \\
Extramedullaryplasmocytomas & 1 & 1 & 2 \\
\hline
\end{tabular}

\section{Results}

\section{Clinical characteristics of patients}

Ninety-six patients were involved in this study, including $42 \mathrm{~K}$-chain $\mathrm{MM}$ patients and $54 \lambda$-chain $\mathrm{MM}$ patients. The basic characteristics of the patients had no significance with the two groups (Tables 1 and 2). All the patients were stage III (DS), including 60 cases of IIIa $(62.5 \%)$ and 36 cases of IIIb (37.5\%). There were 12 (12.5\%) patients with stage I, 26(27.1\%) patients with stage II, $58(60.4 \%)$ patients with stage III according to ISS staging (Table 3). There were 36/96 (37.5\%) patients who had renal failure at the initial onset of the disease and 99/ 369 (27.5\%) patients had renal failure of other type MM, including IgG, IgA and IgD. According to the National Kidney Foundation Practice Guidelines for Chronic Kidney Disease [5], there were 17 patients at stage 2, 12 patients at stage 3 , three patients at stage 4 and four patients at stage 5 . The initial symptoms included bone pain in 74 cases $(77.1 \%)$, weakness in 12 cases $(12.5 \%)$, foamy urine ineight cases (8.3\%), extramedullaryplasmocytomas in two cases $(2.1 \%)$ (Table 4). During the disease progression, there were $78(81.3 \%)$ patients had more than three areas of bone destruction, 26 (27.1\%) patients complicated with pleural effusion, 32 (33.3\%) patients complicated with extramedullaryplasmocytomas, 36 (37.5\%) patients complicated with anemia, four (4.2\%) patients complicated with hypercalcemia, one patient progressed into plasma cell leukemia and one patient complicated with $\mathrm{M}$ protein and skin changes (POEMS) syndrome.

\section{Response analysis}

After four cycles of treatment, the response to therapy for 96 patients were evaluated. The ORR was $95.5 \%$ (63/66), including $56.1 \%(37 / 66) \mathrm{CR}$ and $39.4 \%(26 / 66)$ partial

Table $\mathbf{5}$ The response of 96 light chain multiple myeloma patients

\begin{tabular}{lllll}
\hline Treatment & $\begin{array}{l}\text { Complete } \\
\text { remission } \\
(\text { CR) }\end{array}$ & $\begin{array}{l}\text { Partial } \\
\text { remission } \\
\text { (PR) }\end{array}$ & $\begin{array}{l}\text { Stable } \\
\text { disease } \\
\text { (SD) }\end{array}$ & $\begin{array}{l}\text { Partial } \\
\text { disease } \\
\text { (PD) }\end{array}$ \\
\hline Velcade group $(\mathrm{n}=66)$ & $37(56.1 \%)$ & $26(39.4 \%)$ & $2(3.0 \%)$ & $1(1.5 \%)$ \\
$\begin{array}{l}\text { Without Velcade group } \\
(\mathrm{n}=30)\end{array}$ & $3(10 \%)$ & $15(50 \%)$ & $6(20 \%)$ & $6(20 \%)$ \\
\hline
\end{tabular}

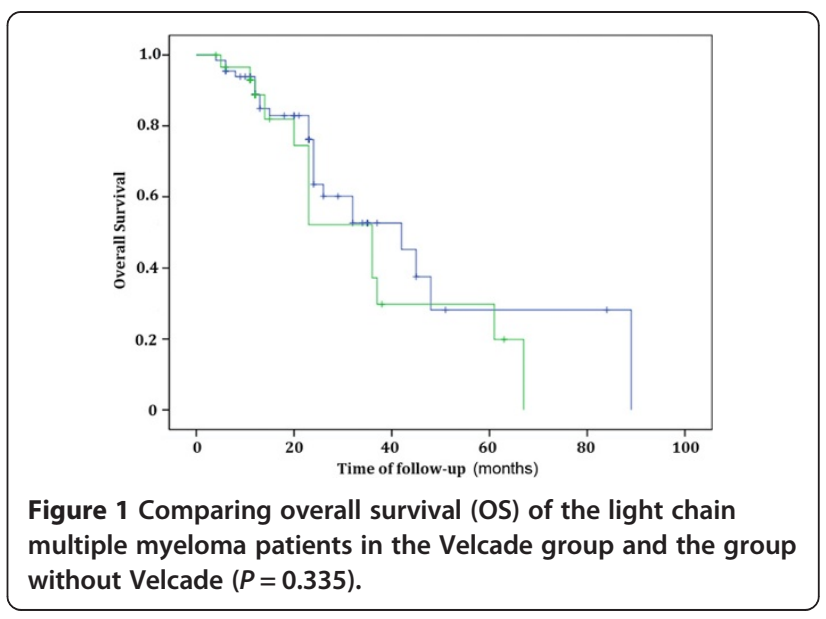

remission (PR) for patients treated with Velcade. The ORR was $60 \%$ (18/30) including 10\% (3/30) CR and 50\% $(15 / 30)$ PR for the patients without Velcade treatment (Table 5).

\section{Survival and prognosis}

At the end of the follow-up on March 31, 2013, there were 25 patients who had died in the Velcade group and 14 patients had died in the group without Velcade treatment. The median time of survival was 23 (four to 89) months in the Velcade group and 12 (four to 67) months in the group without Velcade, respectively. The median time of PFS were nine (three to 36) months for the Velcade group and five (two to 25) months for the group without Velcade, respectively. The three-year OS and five-year OS were $33 \%$ and $24 \%$, respectively for the Velcade group, and were $28 \%$ and $9 \%$ for the group without Velcade. The one-year PFS, two-year PFS and three-year PFS were $37 \%, 25 \%$ and $8 \%$, respectively for the Velcade group. The one-year PFS and two-year PFS were 27\% and $9 \%$ for the group without Velcade. There was no significance with OS between two groups $(P=0.335)$ (Figure 1). However, there was significant difference in

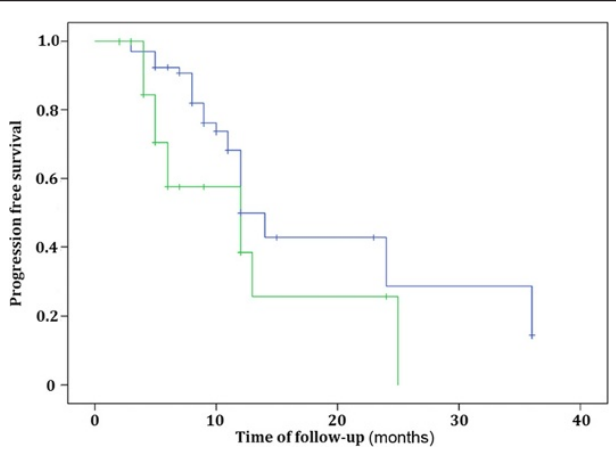

Figure 2 Comparing progression-free survival (PFS) of the light chain multiple myelomapatients in the Velcade group and the group without Velcade $(P=0.036)$. 
PFS between them $(P=0.036)$ (Figure 2). There were 13 patients who lived more than five years in the Velcade group, and only two patients in the group without Velcade. All the 36 patients with renal failure were treated with Velcade. Twelve patients $(70.6 \%)$ with stage 2 renal functionrecovered normal kidney function, three patients (25\%) with stage 3 recovered, three patients with stage 4 and four patients with stage 5 did not recovernormal kidney function, and thus needed dialysis treatment.

\section{Discussion}

In the present study, the clinical profiles of the 96 patients suggested that anemia, bone destruction, pleural effusion,extramedullaryplasmocytomas and renal failure were the most common features of light chain MM. We demonstrated that $33.3 \%$ patients had extramedullary disease, higher than the percentage reported in a previous study [6]. The difference might be explained by the fact that lightchain MM patients in our study had a high tendency of having concomitant extramedullary diseases [7-10].

\section{Conclusion}

Overall, we found that in the patients treated with Velcade, the ORR was $95.5 \%$ (63/66), including 56.1\% (37/66) CR and 39.4\% (26/66) PR. This is significantly higher than the ORR of $60 \%(18 / 30)$ in the patients without Velcade treatment. These results are in line with previous reports [11-13], and strongly suggest the beneficial effect of Velcade on the long-term survival and prognosis for patients with light chain MM.

\section{Consent}

Written informed consent was obtained from the patient for the publication of this report and any accompanying images.

\section{Abbreviations}

CR: Complete remission; CT: Computed tomography; DS: Durie-Salmon staging system; Ig: Immunoglobulin; ISS: International staging system; MM: Multiple myeloma; MRI: Magnetic resonance imaging; ORR: Overall response rate; OS: Overall survival; PFS: Progression-free survival; PR: Partial remission.

\section{Competing interests}

The authors declare that they have no competing interests.

\section{Author's contribution}

JZ and WS constructed the manuscript. JZ, ZH, SC and YZ collected patient's information and conducted experiments. WS, YH, NA and MS analyzed the data. $\mathrm{XL}$ supervised all the procedures and approved the manuscript. All authors read and approved the final manuscript.

\section{Acknowledgements}

Authors thank Yu-ping Zhong MD and Ying Hu for their helpful suggestions.

We also thank Na An MD and Man Shen for their stimulating discussions.

\section{Author details}

'Department of Hematology and Oncology, Beijing Chaoyang Hospital, Capital Medical University, Jingyuan Road, Beijing 100043, China. ${ }^{2}$ Department of Hematology, The Second Artillery General Hospital, Xinwai Road, Beijing 100088, China.

Received: 9 March 2014 Accepted: 4 July 2014

Published: 28 July 2014

\section{References}

1. Kyle RA, Rajkumar SV: Multiple myeloma. N Engl J Med 2004, 351:1860-1873.

2. Kyle RA, Rajkumar SV: Multiple myeloma. Blood 2008, 111:2962-2972.

3. Mateos MV, San Miguel JF: Bortezomib in multiple myeloma. Best Pract Res ClinHaematol 2007, 20:701-715.

4. McBride A, Ryan PY: Proteasome inhibitors in the treatment of multiple myeloma. Expert Rev Anticancer Ther 2013, 13:339-358.

5. Levey AS, Coresh J, Balk E, Kausz AT, Levin A, Steffes MW, Hogg RJ, Perrone RD, Lau J, Eknoyan G: National Kidney Foundation practice guidelines for chronic kidney disease: evaluation, classification, and stratification. Ann Intern Med 2003, 139:137-147.

6. Papanikolaou X, Repousis P, Tzenou T, Maltezas D, Kotsopoulou M, Megalakaki K, Angelopoulou M, Dimitrakoloulou E, Koulieris E, Bartzis V, Pangalis G, Panayotidis P, Kyrtsonis MC: Incidence, clinical features, laboratory findings and outcome of patients with multiple myeloma presenting with extramedullary relapse. Leuk Lymphoma 2013, 54:1459-1464

7. Aguado B, Inigo B, Sastre JL, Oriol A: Extramedullaryplasmacytomas in the context of multiple myeloma. AdvTher 2011, 28:7-13.

8. Varettoni M, Corso A, Pica G, Mangiacavalli S, Pascutto C, Lazzarino M: Incidence, presenting features and outcome of extramedullary disease in multiple myeloma: a longitudinal study on 1003 consecutive patients. Ann Oncol 2010, 21:325-330

9. Terpos E, Rezvani K, Basu S, Milne AE, Rose PE, Scott GL, Rahemtulla A, Samson D, Apperley JF: Plasmacytoma relapses in the absence of systemic progression post-high-dose therapy for multiple myeloma. Eur J Haematol 2005, 75:376-383.

10. Minnema MC, van de Donk NW, Zweegman S, Hegenbart U, Schonland S, Raymakers R, Zijlmans JMJM, Kersten MJ, Bos GMJ, Lokhorst HM: Extramedullary relapses after allogeneic non-myeloablative stem cell transplantation in multiple myeloma patients do not negatively affect treatment outcome. Bone Marrow Transplant 2008, 41:779-784.

11. Gozzetti A, Defina M, Bocchia M, Fabbri A, Marchini E, Chitarrelli I, Lauria F: Safety and efficacy of bortezomib, melphalan and low doses dexamethasone (VM-dex) in newly diagnosed patients with multiple myeloma. Leuk Res 2010, 34:e288-e289.

12. Painuly U, Kumar S: Efficacy of bortezomib as first-line treatment for patients with multiple myeloma. Clin Med Insights Oncol 2013, 7:53-73.

13. Mateos MV, Hernandez JM, Hernandez MT, Gutierrez NC, Palomera L, Fuertes M, Diaz-Mediavilla J, Lahuerta JJ, de la Rubia J, Terol MJ, Sureda A, Bargay J, Ribas P, de Arriba F, Alegre A, Oriol A, Carrera D, Garcia-Larana J, Garcia-Sanz R, Blade J, Prosper F, Mateo G, Esseltine DL, van de Velde H, San Miguel JF: Bortezomib plus melphalan and prednisone in elderly untreated patients with multiple myeloma: results of a multicenter phase 1/2 study. Blood 2006, 108:2165-2172.

doi:10.1186/1477-7819-12-234

Cite this article as: Zhang et al: Light chain multiple myeloma, clinic features, responses to therapy and survival in a long-term study. World Journal of Surgical Oncology 2014 12:234. 